\title{
Students' Perception of Computer Based Approach to Examining Undergraduate Accounting Courses in the University of Maiduguri, Nigeria
}

\author{
Bukar Zanna Waziri Fatima Alfa Tahir* Mary Buba Sani \\ Department of Accounting, University of Maiduguri, P.M.B 1069, Borno State, Nigeria,
}

\begin{abstract}
Conventionally, undergraduate students in Universities are been examined using the paper based approach. However, with the advancements in Information Computer Technology (ICT), universities have introduced the electronic based approach of examination. This paper is an exploratory study that investigates students' perception of computer based approach for examining undergraduate accounting courses in University of Maiduguri. The study was conducted using structured questionnaires administered to 122 purposively selected undergraduate students from four departments who had taken electronic based exams in accounting courses. The Instrument's reliability was established using the Cronbach alpha coefficient and items were found to be consistent in measuring each construct. Data was coded and analyzed with the aid of Statistical package for Social Sciences (SPSS) version 23. The results from the Factor Analysis showed that Students' Assessment of E-exam Facilities, Technical Challenges Encountered by accounting students during e-exams, Students' Views about Enhancing E-exam were principal factors that influenced Students perception of E-exam for examining undergraduate accounting courses in University of Maiduguri.
\end{abstract}

Keywords: Computer Based Examination, Undergraduate Students, Accounting Courses, Nigeria.

DOI: $10.7176 / \mathrm{EJBM} / 11-8-03$

Publication date:March $31^{\text {st }} 2019$

\section{Introduction}

In most tertiary institutions in Nigeria, undergraduate students generally write paper based examinations (PBE). This form of examination involves written exercises where various types of questions such as essays, analytical and numerical calculations are required to be completed within allotted time frames. In the last decade however, several academic institutions and professional bodies including that of accounting have adopted the Computer Based Examination (CBE) approach to examine their students. CBE is an automated system that involves the use of computer and internet in examining students. The students log in to the assessment platform using their registration numbers and attempt the exam using the computer interface by selecting answers from multiple choice questions or filling in the blanks to short answer questions. At the completion of the assessment, they submit and it is forwarded to the system. In other words, it is a process of administering tests in which the responses are electronically recorded, assessed or both. CBE consists of four systems, namely; preparation, examination, monitor and auto-grading subsystem (Zhejiang University China, 2006). In 2014, the University of Maiduguri started converting from the paper based examination (PBE) to CBE. By 2018, the CBE has become the official medium of examining students in the University. This decision was sequel to several factors including increase in the number of students, cases of missing scripts and delays in the processing of students results. However, some departments including Accounting have voiced their concerns on the use of CBE on all courses irrespective of their nature and content.

\section{Literature Review}

Accounting involves identifying, recording, measuring, classifying, verifying summarizing, interpreting, and communicating financial information to both external and internal users. It is a systematic process of demonstrating the practicability of the accounting profession by explaining the meaning of the figures generated. The undergraduate degree in accounting emphasizes oral and written communication skills, ethical behavior, analytical reasoning, and adequate technical knowledge of the accounting profession. Accounting is one of those departments that voiced their concerns on the adoption of CBE by the University management. They argued that the practicality and professionalism of the field may be distorted. This may affect the student's practical and professional skills, employability status and chances of passing professional examinations after graduation from the University.

Numerous scholars have advanced divergent reasons on the use of CBE (Ozden et al, 2004; Cassady and Gridley, 2005; Williams, 2007; Apostolou, Blue \& Daigle, 2009; Marriott \& Lau, 2008; Deutsch et al 2011; Bunker and Flesher 2013; Aiello \& Wolfe, 1980; Burns \& Bozeman, 1981; Chang, 2002; Russell et al, 1997; Sanger \& Greenbowe, 2000). Some of these studies also supported the idea that computer based learning has positive effect on students' performance (Aiello \& Wolfe, 1980; Sanger \& Greenbowe, 2000). In addition, Ozden et al. (2004) and Calarina and Wallace (2002) documented that students perceive the electronic based examination 
as more effective testing mode and impacts positively on their performance as compared to PBE. Furthermore, Ayo et al, (2007) and Schulz, (2009) found that e-assessment systems have the potentials to eliminate some of the problems that are associated with the traditional methods of examination such as impersonation and other forms of examination malpractices. Despite the perceived benefits, some studies have reported CBE has negative effects (Akcay et al, 2002; Powers \& O'neill 1993; Johnson et al. 2004). Other scholars also contend that when students are motivated and testing conditions are same, there are no differences between the scores obtained via computer and paper based exams (Lynch, 1997 \& Marson et al, 2001). However, Evoh (2007) and Adomi and kpangban (2010) posit that most developing countries such as Nigeria have inadequate resources for a sustainable integration of ICTs in education. This has made it difficult for Nigerian educational system to acquire and install ICT facilities for the use of teachers and students (Osei, 2007). There is also acute shortage of trained personnel in application softwares, operating systems, network administration and technicians to service and repair computer facilities as well as enlighten the major stakeholders in the academic institutions (Okebukola, 1997; Anao, 2003).

\section{Research Framework}

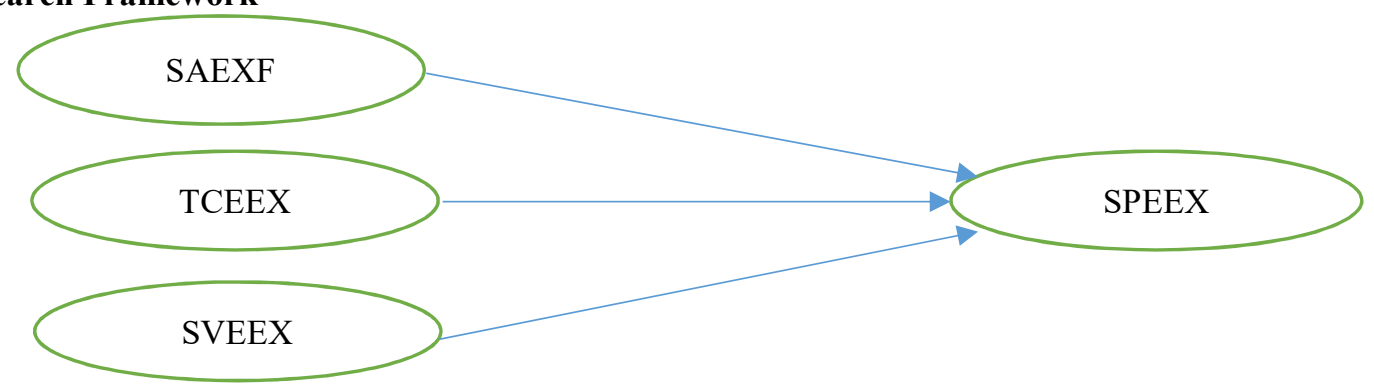

Fig 1: Research Framework

Figure 1 shows three factors, students' assessment of electronic exams facilities (SAEXF), technical challenges encountered during electronic exams (TCEEX) and students' views about enhancing electronic exams (SVEEX) postulated to influence students' perception of electronic examinations (SPEEX). Based on Figure 1, the students' assessment of electronic exams facilities embodies students' feelings about the facilities appeal, functionality, efficiency and effectiveness of the facilities and their acceptance as well as conduciveness of facility environment. The technical challenges encountered during exams captures the difficulties and challenges faced during e-exams such as time limits, system adequacy, maintenance and reliability, staff support, log-in and submission challenges. The students' views about enhancing electronic exams represents students' views on enhancing e-exams such as time adjustments, software specification, tutorials, enlightenment, technical and support services. Put together, these factors are hypothesized to shape students' perception of e-exams (acceptance of the systems, preference and endorsement). Hence, these factors are postulated to constitute the principal factors underlying students' perception of e-exams.

\section{Underpinning Theory}

Based on Innovative and Diffusion Theory, it is argued that invention in the form of ideas or products gain acceptance before being widely used across populations (Rogers, 1962). Thus, people and institutions adapt to new ideas, behavior, and patterns over time, which is totally different from what used to be in practice. The adoption of the new ideas does not happen suddenly in a social system. Rather, it is a gradual process that consist of four stages, awareness of the need for the innovation, decision to adopt or reject the innovation, the initial use of the innovation to test it and finally, the continuous use of the innovation. This study can also be related to the various stages of the theory within the context of the adoption of electronic examination for all accounting courses in the University of Maiduguri. The system requires that the both the students and the departments be enlightened by the management of the University on the reasons for the change to e-based examination. This would make the students and departments to either accept or reject the CBE examination. However, the adoption does not happen simultaneously but it can follow a gradual process. When the key stakeholders accept the CBE, they would decide to test it based on their circumstances and needs. Finally, the continuous use of the CBE would provide opportunity for feedback and improvement. Therefore, the rationale for examining students using the CBE requires adequate availability of ICT infrastructure, manpower, acceptability, gradual implementation, and improvement in the transition process. This suggests that the students view on the adoption of CBE are vital towards the successful implementation of CBE. Since the adoption of the CBE in the University of Maiduguri, there is no study that has investigated the perception of undergraduate management sciences students about the adoption of computer based examination on accounting courses in the university. Based on the foregoing, the following research questions were raised:

i. How do management sciences students assess the electronic based examination for accounting courses?

ii. What are the challenges encountered by management sciences students in using electronic examination 
for accounting courses?

iii. What are the perceptions of management sciences students regarding electronic examination for accounting courses?

iv. What strategies do management sciences students think can enhance electronic examination for accounting courses?

The rest of the paper is structured as follows: the research methods are presented in the succeeding part followed by results, discussions and conclusion.

\section{Research Methods}

In line with previous related works (Ozden, Erturk \& Sanli, 2004; Jimoh et al 2012), this study used survey questionnaire as an instrument to collect the data. The questionnaire used by Jimoh et al (2012) was adapted for this study. Purposive sampling technique was used to select students taking accounting courses from four departments in the faculty of management sciences, University of Maiduguri. A total of 250 questionnaires were distributed to the respondents of which 122 were completed and returned representing $49 \%$ response rate. Table 1 presents the demographic profile of respondents. Table 1 shows $53 \%$ of the respondents were males and majority of them accounting students (54\%). About $74 \%$ of the respondents were in their third and fourth year and $97 \%$ had completed at least six or more accounting courses.

Table 1: Respondents Demographic Profile

\begin{tabular}{|l|r|r|}
\hline Item & Frequency & Percentage \% \\
\hline Gender & & 53.3 \\
\hline Male & 65 & 46.7 \\
\hline Female & 57 & 54.1 \\
\hline Department & & 20.5 \\
\hline Accounting & 66 & 12.3 \\
\hline Business Management & 25 & 13.1 \\
\hline Banking and Finance & 15 & \\
\hline Marketing & 16 & 2.5 \\
\hline Level & & 23.8 \\
\hline 100 & 3 & 26.2 \\
\hline 200 & 29 & 47.5 \\
\hline 300 & 32 & \\
\hline 400 & 58 & 3.3 \\
\hline Number of Accounting courses completed & & \\
\hline $1-5$ & 4 & \\
\hline $6-10$ & 17 & \\
\hline $11-15$ & 22 & 13.9 \\
\hline $16-20$ & 41 & 33.6 \\
\hline 21 and above & 38 & 31.1 \\
\hline
\end{tabular}

\section{Results and Discussions}

The instrument was assessed to establish reliability and internal consistency of measure. Table 4.1 shows the Cronbach alpha coefficient for all variables has exceeded the minimum benchmark of 0.70 (Sekaran \& Bougie, 2010). Hence all item measures are considered reliable and have internal consistency.

Table 2: Reliability Test

\begin{tabular}{|l|c|c|}
\hline \multicolumn{1}{|c|}{ Variable } & No. of Items & Cronbach Alpha \\
\hline Students' Assessment of E-exam Facilities (SAEXF) & 7 & 0.951 \\
\hline Technical Challenges of e-exams (TCEEX) & 9 & 0.953 \\
\hline Students' Views about Enhancing E-exam (SVEEX) & 8 & 0.945 \\
\hline Students Perceptions of E-exam (SPEEX) & 7 & 0.931 \\
\hline
\end{tabular}

\subsection{Exploratory Factor Analysis}

Exploratory Factor analysis (EFA) was carried out using principal component analysis with varimax rotation. Table 3 shows the results from sampling adequacy. The Bartlett's test of sphericity for all variables was significant (.000), the Kaiser-Myer-Olkin (KMO) measure of sampling adequacy is 0.890 which exceeds Hair et al (2010) minimum acceptable benchmark (0.70). The anti-image correlation for each factor along the diagonals were assessed and each item met the 0.50 benchmark indicating that factors are reasonably associated with each other. The communality values (See Appendix 1 ) for all items range from 0.475 to 0.864 (Costello \& Osborne, 2005). The total variance explained (See Appendix1) by the factors having Eigen values $>1$ is $75 \%$ (Hair et al., 2010; 
Williams, Onsman \& Brown, 2010). The rotated factor matrix on table 4 shows all factor loadings are significant $(>.50)$ and load significantly on only one construct. All factors achieved best fit with four constructs loading significantly on only one factor each and all factor loadings are greater than 0.50 . It can therefore be concluded that these factors are valid and are the best factors to be presented in future models.

Table 3: KMO and Bartlett's Test

Kaiser-Meyer-Olkin Measure of Sampling Adequacy.

Bartlett's Test of Sphericity

\begin{tabular}{|l|r|}
\hline Approx. Chi-Square & 3812.148 \\
\hline Df & 465 \\
\hline Sig. & 0.000 \\
\hline
\end{tabular}

Table 4: Rotated Component Matrix ${ }^{\mathrm{a}}$

\begin{tabular}{|c|c|c|c|c|}
\hline & \multicolumn{4}{|c|}{ Component } \\
\hline & 1 & 2 & 3 & 4 \\
\hline SAEXF1 & & & .860 & \\
\hline SAEXF2 & & & .838 & \\
\hline SAEXF3 & & & .828 & \\
\hline SAEXF4 & & & .789 & \\
\hline SAEXF5 & & & .867 & \\
\hline SAEXF6 & & & .872 & \\
\hline SAEXF7 & & & .880 & \\
\hline TCEEX1 & .866 & & & \\
\hline TCEEX2 & .860 & & & \\
\hline TCEEX3 & .805 & & & \\
\hline TCEEX4 & .723 & & & \\
\hline TCEEX5 & .825 & & & \\
\hline TCEEX6 & .785 & & & \\
\hline TCEEX7 & .872 & & & \\
\hline TCEEX8 & .837 & & & \\
\hline TCEEX9 & .793 & & & \\
\hline SPEEX1 & & .746 & & \\
\hline SPEEX2 & & .655 & & \\
\hline SPEEX3 & & .766 & & \\
\hline SPEEX4 & & .812 & & \\
\hline SPEEX5 & & .840 & & \\
\hline SPEEX6 & & .820 & & \\
\hline SPEEX7 & & .890 & & \\
\hline SPEEX8 & & .868 & & \\
\hline SVEEX1 & & & & .573 \\
\hline SVEEX2 & & & & .833 \\
\hline SVEEX3 & & & & .827 \\
\hline SVEEX4 & & & & .896 \\
\hline SVEEX5 & & & & .863 \\
\hline SVEEX6 & & & & .865 \\
\hline SVEEX7 & & & & .859 \\
\hline
\end{tabular}

Extraction Method: Principal Component Analysis. Rotation Method: Varimax with Kaiser Normalization.

a. Rotation converged in 6 iterations.

\section{Conclusion}

The paper conducted an exploratory study on the perception of management science students on Computer Based Approach to Examining Undergraduate Accounting Courses in the University of Maiduguri. Exploratory study is necessary to establish preliminary results before the main study as recommended by prior studies. The content validity and reliability of the instrument were also established since all minimum benchmarks were met. The Exploratory Factor Analysis (EFA) using Principal Component Analysis (PCA) with varimax rotation showed the four factors were distinct and valid constructs as all item factor loadings exceeded 0.50 and the KMO was above 0.70 and significant. This shows that all variables studied are valid measures of factors influencing perceptions of students regarding computer based approach to examining accounting courses in the University of Maiduguri. 


\section{References}

Abdulkareem A. Y. and Alabi, A.T. (2004). Curbing examination malpractice in the University system: A management perspective. Nigerian Journal of Education Researchers and Evaluators. 5(1), 19-26.

Abubakar, A. S., \& Adebayo, F. O. (2014). Using computer based test method for the conduct of examination in Nigeria: Prospects, challenges, and strategies. Mediterranean Journal of Social Sciences, 5(2), 47.

Akcay, H., Durmaz, A., Tuysuz, C., \& Feyzioglu, B. (2006). Effects of Computer Based Learning on Students' Attitudes and Achievements towards Analytical Chemistry. Online Submission, 5(1).

Apostolou, B., Blue, M. A., \& Daigle, R. J. (2009). Student perceptions about computerized testing in introductory managerial accounting. Journal of Accounting Education, 27(2) 59-70.

Ayo, C. K., Akinyemi, I. O., Adebiyi, A. A., \& Ekong, U. O. (2007). The prospects of e-examination implementation in Nigeria. Turkish Online Journal of Distance Education-TOJDE, 8(4), 125-134.

Betlej P. (2013). E-Examinations from Student's Perspective-the Future of Knowledge Evaluation. Studia Ekonomiczne, 153, 9-22.

Birch, D., \& Burnett, B. (2009). Bringing academics on board: Encouraging Institution-wide diffusion of elearning environments. Australasian Journal of Educational Technology, 25(1), 117-134.

Bunker, R. B., \& Flesher, T. K. (2013). The Computer-Based CPA Exam: Have Changes Impacted Perceptions of the Prestige of CPA Certification? Journal of Higher Education Theory and Practice, 13(2), 56-67.

Cassady, J. C., \& Gridley, B. E. (2005). The Effects of Online Formative and Summative Assessment on Test Anxiety and Performance. Journal of Technology, Learning, and Assessment, 4(1), 1-31.

Costello, A. B., \& Osborne, J. W. (2005). Best practices in exploratory factor analysis: Four recommendations for getting the most from your analysis. Practical assessment, research \& evaluation, 10(7), 1-9.

Fonolahi, A. V., Khan, M. G., \& Jokhan, A. D. (2014). Are students studying in the online mode faring as well as students studying in the face-to-face mode? Has equivalence in learning been achieved? Journal of Online Learning and Teaching, 10(4), 598-609.

Hair, J., Anderson, R., Tatham, R., \& Black, W. (2010). Multivariate Data Analysis. Upper Saddle River, NJ: Prentice-Hall International.

Hewson, C. (2012). Can online course based assessment methods be fair and equitable? Relationships between students' preferences and performance within online and offline assessments. Journal of Computer Assisted Learning, 28(5), 488-498.

Hurley, A. (2017). Exploring the Use of Computer Based Exams for Undergraduate Accounting. Irish Journal of Academic Practice, 6(1), 1-23.

Iyilade, J. S., \& Odekunle, W. O. (2005). A web-based student testing and assessment system. In Proceedings of the International Conference on Application of ICT to teaching, research, and administration, AICTTRA, 1, 16-24.

Jimoh, R. G., Shittu, A. J. K., \& Kawu, Y. K. (2012). Students' perception of computer based test (CBT) for examining undergraduate chemistry courses. Journal of Emerging Trends in Computing and Information Sciences, 3(2), 125-134.

Lockwood, S. R., Nally, J. M., Dowdell, J., McGlone, J., \& Steurer, S. (2013). Implementing the 2014 Ged Exam and Computer-Based Ged Testing in Correctional Facilities: A Guide for Correctional Educators and Administrators. Journal of Correctional Education, 64(2).

Osuji, U. S. (2012). The use of e-assessments in the Nigerian higher education system. Turkish Online Journal of Distance Education, 13(4), 140-152.

Sekaran, U., \& Bougie, R. (2010). Research methods for business: A skill building approach (5th ed., 1-387). United Kindom: John Wiley \& Sons Ltd.

Tabachnick, B. G., \& Fidell, L. S. (2007). Using multivariate statistics. Allyn \& Bacon/Pearson Education.

Williams, B., Onsman, A., \& Brown, T. (2010). Exploratory Factor Analysis: A five-step guide for novices. Australian Journal of Paramedicine, 8(3), 1-13. 


\section{Appendix 1}

\begin{tabular}{|c|c|c|}
\hline \multicolumn{3}{|c|}{ Communalities } \\
\hline & Initial & Extraction \\
\hline SAEXF1 & 1.000 & .825 \\
\hline SAEXF2 & 1.000 & .756 \\
\hline SAEXF3 & 1.000 & .745 \\
\hline SAEXF4 & 1.000 & .726 \\
\hline SAEXF5 & 1.000 & .814 \\
\hline SAEXF6 & 1.000 & .780 \\
\hline SAEXF7 & 1.000 & .823 \\
\hline TCEEX1 & 1.000 & .854 \\
\hline TCEEX2 & 1.000 & .840 \\
\hline TCEEX3 & 1.000 & .731 \\
\hline TCEEX4 & 1.000 & .630 \\
\hline TCEEX5 & 1.000 & .747 \\
\hline TCEEX6 & 1.000 & .648 \\
\hline TCEEX7 & 1.000 & .801 \\
\hline TCEEX8 & 1.000 & .716 \\
\hline TCEEX9 & 1.000 & .689 \\
\hline SPEEX1 & 1.000 & .702 \\
\hline SPEEX2 & 1.000 & .668 \\
\hline SPEEX3 & 1.000 & .640 \\
\hline SPEEX4 & 1.000 & .708 \\
\hline SPEEX5 & 1.000 & .742 \\
\hline SPEEX6 & 1.000 & .802 \\
\hline SPEEX7 & 1.000 & .879 \\
\hline SPEEX8 & 1.000 & .864 \\
\hline SVEEX1 & 1.000 & .475 \\
\hline SVEEX2 & 1.000 & .724 \\
\hline SVEEX3 & 1.000 & .706 \\
\hline SVEEX4 & 1.000 & .846 \\
\hline SVEEX5 & 1.000 & .780 \\
\hline SVEEX6 & 1.000 & .781 \\
\hline SVEEX7 & 1.000 & .817 \\
\hline
\end{tabular}

Extraction Method: Principal Component Analysis. 


\begin{tabular}{|c|c|c|c|c|c|c|c|c|c|}
\hline \multicolumn{10}{|c|}{ Total Variance Explained } \\
\hline \multirow[b]{2}{*}{ Component } & \multicolumn{3}{|c|}{ Initial Eigenvalues } & \multicolumn{3}{|c|}{ Extraction Sums of Squared Loadings } & \multicolumn{3}{|c|}{ Rotation Sums of Squared Loadings } \\
\hline & Total & $\begin{array}{c}\% \text { of } \\
\text { Variance }\end{array}$ & Cumulative $\%$ & Total & $\begin{array}{c}\% \text { of } \\
\text { Variance }\end{array}$ & Cumulative \% & Total & $\begin{array}{c}\% \text { of } \\
\text { Variance }\end{array}$ & Cumulative $\%$ \\
\hline 1 & 11.916 & 38.438 & 38.438 & 11.916 & 38.438 & 38.438 & 6.675 & 21.531 & 21.531 \\
\hline 2 & 4.431 & 14.295 & 52.732 & 4.431 & 14.295 & 52.732 & 5.882 & 18.975 & 40.505 \\
\hline 3 & 3.739 & 12.061 & 64.793 & 3.739 & 12.061 & 64.793 & 5.594 & 18.045 & 58.551 \\
\hline 4 & 3.176 & 10.245 & 75.038 & 3.176 & 10.245 & 75.038 & 5.111 & 16.487 & 75.038 \\
\hline 5 & .738 & 2.382 & 77.420 & & & & & & \\
\hline 6 & .712 & 2.296 & 79.716 & & & & & & \\
\hline 7 & .593 & 1.913 & 81.628 & & & & & & \\
\hline 8 & .557 & 1.798 & 83.427 & & & & & & \\
\hline 9 & .494 & 1.593 & 85.020 & & & & & & \\
\hline 10 & .438 & 1.413 & 86.433 & & & & & & \\
\hline 11 & .412 & 1.329 & 87.762 & & & & & & \\
\hline 12 & .396 & 1.279 & 89.041 & & & & & & \\
\hline 13 & .375 & 1.210 & 90.251 & & & & & & \\
\hline 14 & .335 & 1.080 & 91.330 & & & & & & \\
\hline 15 & .295 & .950 & 92.281 & & & & & & \\
\hline 16 & .266 & .857 & 93.137 & & & & & & \\
\hline 17 & .251 & .808 & 93.946 & & & & & & \\
\hline 18 & .237 & .765 & 94.710 & & & & & & \\
\hline 19 & .213 & .689 & 95.399 & & & & & & \\
\hline 20 & .199 & .642 & 96.042 & & & & & & \\
\hline 21 & .190 & .611 & 96.653 & & & & & & \\
\hline 22 & .172 & .554 & 97.207 & & & & & & \\
\hline 23 & .160 & .515 & 97.722 & & & & & & \\
\hline 24 & .149 & .482 & 98.204 & & & & & & \\
\hline 25 & .117 & .377 & 98.581 & & & & & & \\
\hline 26 & .108 & .348 & 98.929 & & & & & & \\
\hline 27 & .095 & .307 & 99.236 & & & & & & \\
\hline 28 & .084 & .270 & 99.506 & & & & & & \\
\hline 29 & .069 & .222 & 99.729 & & & & & & \\
\hline 30 & .053 & .172 & 99.901 & & & & & & \\
\hline 31 & .031 & .099 & 100.000 & & & & & & \\
\hline
\end{tabular}

Extraction Method: Principal Component Analysis.

Dr. Bukar Zanna Waziri (PhD) was born in 1982 in kukawa in Borno State, Nigeria. He is currently a lecturer in the department of accounting, University of Maiduguri-Nigeria. Dr. Waziri lectures and supervises students both at undergraduate and postgraduate levels. Philosophically, he is a pragmatist, who believe in the ideas of pluralism as a basis of understanding social reality. He has a strong background in accounting and studied M.Sc. in oil and gas accounting and $\mathrm{PhD}$ both at Abertay University, UK. He has special interest in research, energy, petroleum, environmental accounting and other accounting related areas. He designed and introduced oil and gas accounting as a course at the undergraduate level and presently the final year level coordinator. Dr. Waziri has published and co-authored many journal articles and presented papers in several conferences. He is a reviewer of several journal papers for both international and national journals and a member of the British Accounting and Finance Association.

Dr. Fatima Alfa Tahir was born in Zaria, Nigeria in 1975. She holds a bachelor's degree in accounting, masters degrees in accounting and banking and finance from the University of Maiduguri. She holds a PhD in accounting from the Universiti Utara Malaysia, specializing in auditing and research. She is a senior lecturer with the department of accounting, University of Maiduguri and a member of the Association of National Accountants of Nigeria (ANAN) and the Nigerian Accounting Association (NAA). She has authored several papers in both local and international journals. She is presently the coordinator, postgraduate diploma in accounting (PGDA) programme, University of Maiduguri. Dr. Fatima lectures diploma, distance learning, undergraduate and postgraduate students of accounting and business management. She is happily married with children.

Mary Buba Sani was born in Maiduguri, Nigeria in 1997. She holds a bachelor's degree in Accounting (First class). She is from Madagali local government area of Adamawa state. She is currently undertaking her national youth service at the bursary department, federal college of education (Technical) Gombe state. 